\title{
Laparoscopy versus laparotomy for the management of early stage cervical cancer

\author{
Yan-zhou Wang ${ }^{1}$, Li Deng ${ }^{1}$, Hui-cheng Xu', Yao Zhang ${ }^{2^{* \dagger}}$ and Zhi-qing Liang ${ }^{1 *+}$
}

\begin{abstract}
Background: The possible advantages of laparoscopic radical hysterectomy (LRH) versus open radical hysterectomy $(\mathrm{RH})$ have not been well reviewed systematically. The aim of this study was to systematically review the comparative effectiveness between $\mathrm{LH}$ and $\mathrm{RH}$ in the treatment of cervical cancer based on the evaluation of the Perioperative outcomes, oncological clearance, complications and long-term outcomes.

Methods: The systematic review was conducted by searching PubMed, MEDLINE, EMBASE, the Cochrane Library and BIOSIS databases. All original studies that compared LRH with RH were included for critical appraisal. Data were pooled and analyzed.

Results: A total of twelve original studies that compared LRH $(n=754)$ with RH $(n=785)$ in patients with cervical cancer fulfilled quality criteria were selected for review and meta-analysis. LRH compared with RH was associated with a significant reduction of intraoperative blood loss (weighted mean difference $=-268.4 \mathrm{~mL}(95 \% \mathrm{Cl}$ $-361.6,-175.1 ; p<0.01)$, a reduced risk of postoperative complications $(\mathrm{OR}=0.46 ; 95 \% \mathrm{Cl} 0.34-0.63)$ and shorter hospital stay (weighted mean difference $=-3.22$ days; $95 \% \mathrm{Cl}-4.21,-2.23$ days; $p<0.01$ ). These benefits were at the cost of longer operative time (weighted mean difference $=26.9$ min $(95 \% \mathrm{Cl} 8.08-45.82)$.

The rate of intraoperative complications was similar in the two groups. Lymph nodes yield and positive resection margins were similar between the two groups. There were no significant differences in 5-year

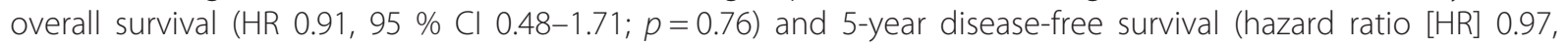
$95 \% \mathrm{Cl} 0.56-1.68 ; p=0.91)$.
\end{abstract}

Conclusions: LRH shows better short term outcomes compared with $\mathrm{RH}$ in patients with cervical cancer. The oncologic outcome and 5-year survival were similar between the two groups.

Keywords: Laparoscopic radical hysterectomy, Abdominal radical hysterectomy, Meta-analysis, Cervical cancer

\section{Background}

Cervical cancer is the fourth most common cancer in women, and the seventh overall. It accounts for $7.5 \%$ of all female cancer deaths with approximately 266,000 deaths worldwide in 2012. Almost nine out of ten cervical cancer deaths occur in the less developed regions. In countries that do not have access to cervical cancer screening and prevention programs, cervical cancer remains the second most common type of cancer (17.8

\footnotetext{
*Correspondence: sydzy2003@aliyun.com; zhi.|zliang@gmail.com ${ }^{\dagger}$ Equal contributors

${ }^{2}$ Department of Epidemiology, Clinic Epidemiology Center, Third Military Medical University, Chongqing 400038, People's Republic of China

'Department of Obstetrics and Gynecology, Southwest Hospital, Third Military Medical University, Chongqing 400038, People's Republic of China
}

per 100,000 women) and cause of cancer deaths (9.8 per $100,000)$ among all types of cancer in women $[1,2]$.

Radical hysterectomy with pelvic lymphadenectomy is the standard surgical treatment for patients with early stage cervical cancer [3]. Although the majority of radical hysterectomies are performed with the open technique, laparoscopic, combined laparoscopic and vaginal and robotic-assisted approaches have been used at several centers [4-7]. Compared with the abdominal radical hysterectomy, laparoscopic techniques are associated with less blood loss, shorter hospital stay, better cosmesis and faster recovery, but questions still remain about comparative effectiveness with respect to oncological clearance, complications, recurrence rates and long-term outcomes [8]. Studies comparing laparoscopy with

\section{() Biomed Central}

(c) 2015 Wang et al. Open Access This article is distributed under the terms of the Creative Commons Attribution 4.0 International License (http://creativecommons.org/licenses/by/4.0/), which permits unrestricted use, distribution, and reproduction in any medium, provided you give appropriate credit to the original author(s) and the source, provide a link to the Creative Commons license, and indicate if changes were made. The Creative Commons Public Domain Dedication waiver (http://creativecommons.org/publicdomain/zero/1.0/) applies to the data made available in this article, unless otherwise stated. 
conventional open surgery are limited by their sample sizes and are not individually powered to detect small differences in outcomes. A pooled synthesis of these studies using meta-analysis may provide further insights into the safety and comparative effectiveness of laparoscopy and conventional open surgery.

Systematic reviews and meta-analyses have shown an advantage in short-term outcomes of laparoscopic (assisted vaginal) and robotic radical hysterectomy compared with open distal radical hysterectomy [9]. Kucukmetin carried out a systematic review of randomized controlled trials (RCTs) studies that compared open and laparoscopic assisted vaginal radical hysterectomy (LAVH) in women with early cervical cancer, but found only one relevant trial which included an exceptionally small number of 13 cases. Due to the small number of cases and the short term scope of the trial, this article was unable to reach any definite conclusions regarding the relative benefits and harms of the two forms of treatment [10]. Thus far, the potential benefits and disadvantages of LRH have not been subjected to a scrupulous systematic review.

The aim of this study was to compare minimally invasive surgery, in particular, total laparoscopic radical hysterectomy (LRH) with open radical hysterectomy (RH) with respect to perioperative outcomes, oncological clearance, complications and long-term outcomes.

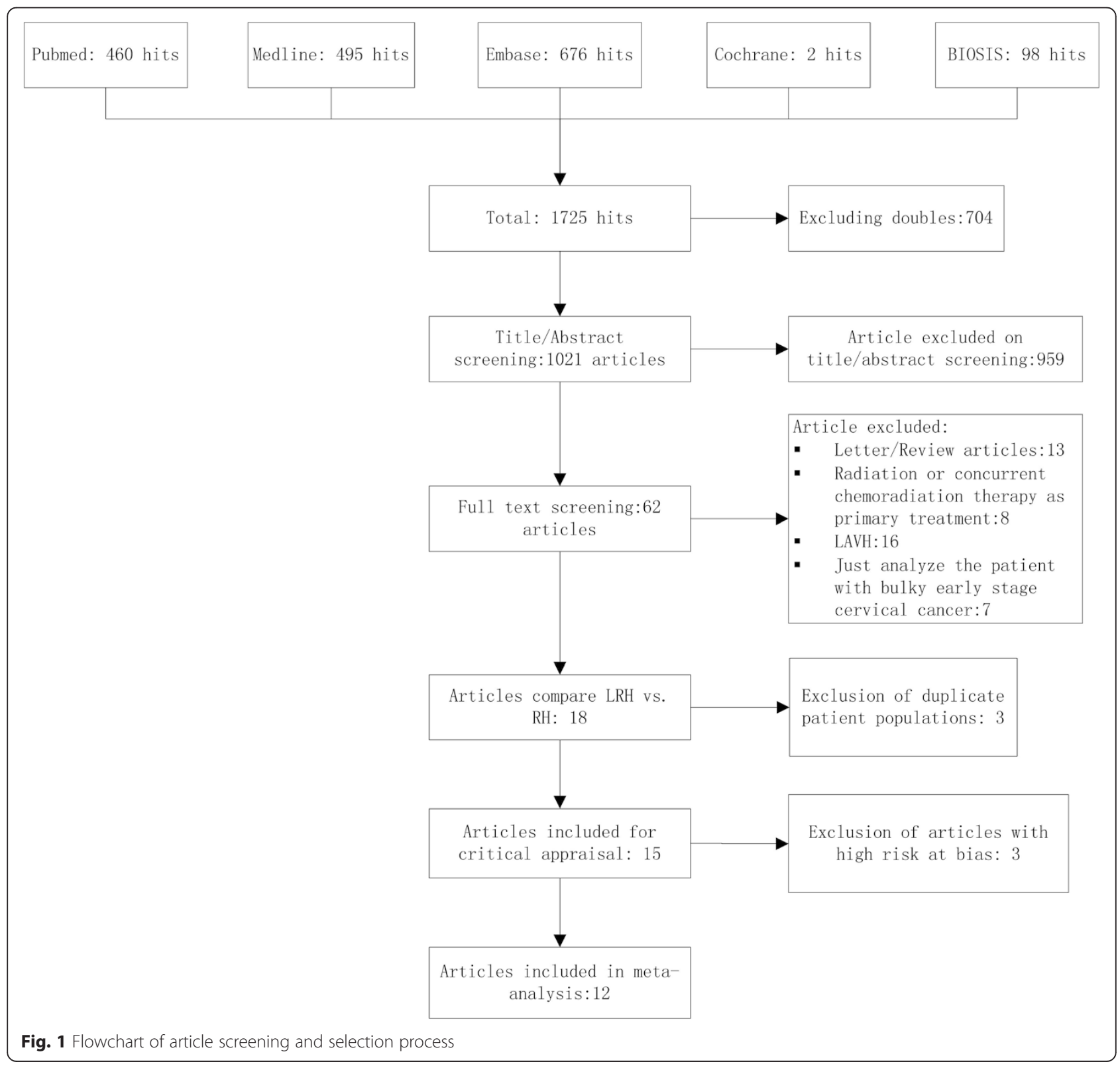




\section{Methods}

\section{Database searching strategy}

This review was conducted according to the MOOSE guidelines for systematic reviews [11]. PubMed, MEDLINE, EMBASE, the Cochrane Library and BIOSIS databases were searched for: "cervical cancer" AND "laparoscopic" AND "radical hysterectomy" along with their synonyms or abbreviations. No additional search software or special features were used. The last search update was in December, 2014. The investigators (Yanzhou Wang and Yao Zhang) independently performed the screening and article selection procedures. All articles that fulfilled the eligibility criteria were included in the systematic review. Authors were contacted by email in cases where full-text articles were not available.

\section{Inclusion and exclusion criteria}

Studies included in this analysis must have met the following criteria: (1) adult women diagnosed with cervical cancer; (2) women who had undergone LRH versus $R H$ as primary treatment; (3) patients who were classified as International Federation of Gynecology and Obstetrics (FIGO) stage IA1 with lymphovascular invasion to IIA. Studies were excluded from the meta-analysis if (1) radiation or concurrent chemoradiation therapy were used as primary treatment, (2) the surgical approach used was laparoscopic assisted radical vaginal hysterectomy. In the case of multiple studies with the same or overlapping data published by the same researchers, we selected the most recent study with the largest number of participants. Using these criteria, duplicate publications with derivative patients were excluded from our meta-analysis $[12,13]$. One article was excluded for only including patients with stages IB2 and IIA2 and, therefore, is not comparable to this current study because this patient population includes stages IA1 through IIA2 [14].

\section{Data extraction}

The following data were collected from each study: first author's surname, year of publication, country, participant characteristics, study design, sample size, blood

Table 1 Main characteristics of 11 studies of $\mathrm{LRH}$ and $\mathrm{RH}$

\begin{tabular}{|c|c|c|c|c|c|c|c|c|c|c|c|}
\hline \multirow[t]{2}{*}{ References } & \multirow[t]{2}{*}{ Design } & \multirow[t]{2}{*}{ Approach } & \multirow[t]{2}{*}{ Number } & \multirow[t]{2}{*}{ Age (years) } & \multirow{2}{*}{$\begin{array}{l}\text { BMI } \\
(\mathrm{Kg} / \mathrm{m} 2)\end{array}$} & \multirow{2}{*}{$\begin{array}{l}\text { Tumor } \\
\text { diameter }(\mathrm{cm})\end{array}$} & \multicolumn{5}{|l|}{ Stage } \\
\hline & & & & & & & la1 (LVSI) & la2 & lb1 & lb2 & $\overline{\| l a}$ \\
\hline \multirow[t]{2}{*}{ Bogani et al. [31] } & Propensity-matched cohort & Laparoscopic & 65 & $48.9 \pm 13.5$ & $25.1 \pm 5.2$ & - & - & - & - & - & - \\
\hline & & Open & 65 & $50.9 \pm 14$ & $25.9 \pm 6.1$ & - & - & - & - & - & - \\
\hline \multirow[t]{2}{*}{ Chen et al. [20] } & Retrospective cohort & Laparoscopic & 32 & $51.2 \pm 11.9$ & $23.2 \pm 3.4$ & - & - & - & - & - & - \\
\hline & & Open & 44 & $51.9 \pm 11.3$ & $24.9 \pm 4.6$ & - & - & - & - & - & - \\
\hline \multirow[t]{2}{*}{ Ditto et al. [25] } & Propensity-matched cohort & Laparoscopic & 60 & $46 \pm 12.5$ & $24.3 \pm 2.9$ & - & - & 13 & 47 & - & - \\
\hline & & Open & 60 & $45.5 \pm 15.75$ & $24.0 \pm 4.3$ & - & - & 10 & 50 & - & - \\
\hline \multirow[t]{2}{*}{ Frumovitz et al. [26] } & Retrospective cohort & Laparoscopic & 35 & $40.8 \pm 8.75$ & $28.1 \pm 5.6$ & - & 2 & 5 & 28 & 0 & - \\
\hline & & Open & 54 & $42.5 \pm 10.25$ & $28.2 \pm 7.25$ & - & 3 & 8 & 42 & 1 & - \\
\hline \multirow[t]{2}{*}{ Ghezzi et al. [27] } & cohort & Laparoscopic & 50 & $47 \pm 13.5$ & $23 \pm 4.4$ & $2.6 \pm 0.9$ & - & 7 & 30 & 6 & 7 \\
\hline & & Open & 48 & $53 \pm 11.8$ & $25 \pm 6.0$ & $3.0 \pm 1.0$ & - & 2 & 26 & 13 & 7 \\
\hline \multirow[t]{2}{*}{ Lee et al. [21] } & Retrospectivecohort & Laparoscopic & 24 & $48.4 \pm 7.25$ & $23.4 \pm 3.55$ & - & - & 5 & 13 & 2 & 4 \\
\hline & & Open & 48 & $50.2 \pm 8.25$ & $23.9 \pm 4.7$ & - & - & 10 & 26 & 4 & 8 \\
\hline \multirow[t]{2}{*}{ Li et al. [22] } & Retrospectivecohort & Laparoscopic & 90 & $42 \pm 9$ & - & $2.8 \pm 1.4$ & - & & 60 & 12 & 18 \\
\hline & & Open & 35 & $44 \pm 11$ & - & $2.6 \pm 1.5$ & - & & 14 & 8 & 13 \\
\hline \multirow[t]{2}{*}{ Lim et al. [23] } & Prospectivecohort & Laparoscopic & 18 & $47.8 \pm 8.8$ & $23.9 \pm 4.4$ & $2.9 \pm 1.5$ & - & 2 & 13 & 3 & 0 \\
\hline & & Open & 30 & $47.0 \pm 8.5$ & $22.4 \pm 4$ & $3 \pm 1.2$ & - & 1 & 23 & 4 & 2 \\
\hline \multirow[t]{2}{*}{ Malzoni et al. [28] } & Retrospectivecohort & Laparoscopic & 65 & $40.5 \pm 7.7$ & $26.0 \pm 4$ & & 5 & 21 & 39 & - & - \\
\hline & & Open & 62 & $42.7 \pm 8.6$ & $29.0 \pm 4$ & & 3 & 11 & 48 & - & - \\
\hline \multirow[t]{2}{*}{ Nam et al. [24] } & Retrospectivematched cohort & Laparoscopic & 263 & 46.4 & 23.2 & $1.8 \pm 0.55$ & - & 36 & 197 & 25 & 5 \\
\hline & & Open & 263 & 46.5 & 23.9 & $1.8 \pm 0.75$ & - & 40 & 194 & 21 & 8 \\
\hline \multirow[t]{2}{*}{ Toptas et al. [29] } & Retrospectivecohort & Laparoscopic & 22 & - & - & $2.1 \pm 1.5$ & - & 9 & 13 & - & - \\
\hline & & Open & 46 & - & - & $2.6 \pm 1.07$ & - & 7 & 39 & & - \\
\hline \multirow[t]{2}{*}{ Zakashansky et al. [30] } & Retrospectivematched cohort & Laparoscopic & 30 & $48.3 \pm 12.25$ & - & - & 1 & 8 & 17 & 2 & 2 \\
\hline & & Open & 30 & $46.6 \pm 11.75$ & - & - & 1 & 6 & 19 & 2 & 2 \\
\hline
\end{tabular}


loss, transfusion rate, operative time, duration of hospital stay, intraoperative complications, postoperative complications, oncologic outcome (resection margins and mean nodal counts), recurrence rate, 5-year disease free survival (DFS) and 5-year overall survival (OS). If data could be acquired from the tabulated literature search results, they would be extracted carefully into $2 \times 2$ tables from all eligible publications by two independent reviewers, based on the inclusion criteria above. In the study, medians were presented instead of means. Based on these medians, the means were estimated as (low end of range + median* $2+$ high end of range) $/ 4$ for a sample size smaller than 25 . For a sample size larger than 25, the median was used as an estimation for the mean. When only a range was provided, the standard deviations were estimated as range/4 [15]. With data regarding OS and DFS, HRs with $95 \%$ confidence interval were not reported, data were extracted from the survival curves and mathematical HR approximations were performed using established methods [16, 17]. If data were not directly available, they would be calculated from published positive predictive values and/or negative predictive values. If there was unclear or incomplete information in the studies, the reviewers would contact the original authors for verification. Disagreements were resolved through discussion between the two reviewers.

\section{Quality evaluation}

The NOS (Newcastle-Ottawa scale) is a tool that judges and evaluates non-randomized studies in meta-analyses
[18]. The scores ranged from 0 to 9 stars. Studies with scores of 7 stars or greater were considered to be of high quality. The stars were added up to compare the quality of the study in a quantitative fashion. Two reviewers independently evaluated and cross-checked the qualities of the included studies, as well as assessed the bias of the studies. An open discussion was held to confirm the scores of those studies that caused disagreements between the reviewers.

\section{Statistical methods}

All statistical tests were performed using the Cochrane Collaboration's Revman5.1. Continuous data are expressed as mean differences with standard deviations (SD). Results for comparisons of dichotomous outcomes (e.g., major postoperative complications) are expressed as risk differences [or absolute risk reduction, ARR) with $95 \%$ confidence intervals (CI)]. A meta-analysis was planned if the included studies were clinically homogeneous. Heterogeneity among studies was determined by the Chi-square-based $Q$ test and the $I^{2}$ statistics. A $p$ value less than 0.05 for the $Q$ test together with an $I^{2}$ value greater than $50 \%$ was considered a measure of severe heterogeneity. Therefore, the study was calculated using the fixed-effect model (the Mantel-Haenszel method), otherwise, the random-effects model (the DerSimonian and Laird method) was used [19]. The publication bias for each of the pooled study groups was assessed with a funnel plot. A two-tailed test was used

Table 2 Assessment of study quality

\begin{tabular}{|c|c|c|c|c|c|c|c|c|c|c|}
\hline \multirow[t]{3}{*}{ Study } & \multicolumn{9}{|c|}{ Quality indicators from Newcastle-Ottawa scale } & \multirow[t]{3}{*}{ Score } \\
\hline & \multicolumn{4}{|c|}{ Selection } & \multicolumn{2}{|c|}{ Comparability } & \multicolumn{3}{|c|}{ Exposure/outcome } & \\
\hline & 1 & 2 & 3 & 4 & $5 a$ & $5 b$ & 6 & 7 & 8 & \\
\hline Bogani et al. [31] & Yes & $\mathrm{NO}$ & Yes & Yes & Yes & Yes & Yes & Yes & Yes & 9 \\
\hline Chen et al. [20] & Yes & Yes & Yes & Yes & Yes & Yes & Yes & No & Yes & 8 \\
\hline Ditto et al. [25] & Yes & Yes & Yes & Yes & Yes & Yes & Yes & Yes & Yes & 9 \\
\hline Frumovitz et al. [26] & Yes & Yes & No & Yes & Yes & Yes & Yes & No & Yes & 7 \\
\hline Ghezzi et al. [27] & Yes & Yes & No & Yes & Yes & Yes & Yes & No & Yes & 7 \\
\hline Lee et al. [21] & Yes & Yes & Yes & Yes & Yes & Yes & Yes & Yes & Yes & 9 \\
\hline Li et al. [22] & Yes & Yes & Yes & Yes & Yes & No & Yes & No & No & 6 \\
\hline Lim et al. [23] & Yes & Yes & Yes & Yes & Yes & No & Yes & No & Yes & 7 \\
\hline Malzoni et al. [28] & Yes & Yes & No & Yes & Yes & Yes & Yes & Yes & Yes & 8 \\
\hline Nam et al. [24] & Yes & Yes & Yes & Yes & Yes & No & Yes & Yes & Yes & 8 \\
\hline Toptas et al. & Yes & Yes & Yes & Yes & Yes & Yes & Yes & No & Yes & 8 \\
\hline Zakashansky et al. [30] & Yes & Yes & Yes & Yes & Yes & Yes & Yes & No & No & 7 \\
\hline
\end{tabular}

For case-control studies, 1 indicates cases independently validated; 2 cases are consecutive or representative of population; 3 communitycontrols; 4 controls have no history of cervical cancer ; $5 \mathrm{~A}$ study controls for sex and age; $5 \mathrm{~B}$ study controls for any additional factor(s); 6 ascertainment ofexposure by secure record or blinded interview; 7 same method of ascertainment for cases and controls; and 8 same non-response rate for casesand controls. For cohort studies, 1 indicates exposed cohort truly representative, 2 the non-exposed cohort drawn from the same community, 3ascertainment of exposure by secure record or structured interview, 4 outcome of interest was not present at start of study, 5A cohorts comparableon basis of sex and age, 5B cohorts comparable on other factor(s), 6 quality of outcome assessment, 7 follow-up long enough for outcomes tooccur; and 8 complete follow-up 
Table 3 Study outcomes

\begin{tabular}{|c|c|c|c|c|c|c|c|c|c|c|c|}
\hline References & Approach & Number & $\begin{array}{l}\text { Operative } \\
\text { time (min) }\end{array}$ & Blood loss (ml) & $\begin{array}{l}\text { Transfusion } \\
\text { rate (\%) }\end{array}$ & Nodal counts & $\begin{array}{l}\text { Duration of } \\
\text { hospital stay }\end{array}$ & $\begin{array}{l}\text { Removal of } \\
\text { foley catheter }\end{array}$ & $\begin{array}{l}\text { Surgical margins } \\
\text { positive }\end{array}$ & $\begin{array}{l}\text { 5-years disease } \\
\text { free survival, (\%) }\end{array}$ & $\begin{array}{l}\text { 5-years overall } \\
\text { survival, (\%) }\end{array}$ \\
\hline \multirow[t]{2}{*}{ Bogani et al. [31] } & Laparoscopic & 65 & $245 \pm 72.2$ & $200 \pm 297.5$ & $4(6)$ & $23.2 \pm 8.2$ & $4 \pm 3.3$ & - & - & $83 \%$ & $89 \%$ \\
\hline & Open & 65 & $259.5 \pm 69.6$ & $500 \pm 475$ & $14(22)$ & $27.4 \pm 17.2$ & $8 \pm 1.8$ & - & - & $80 \%$ & $83 \%$ \\
\hline \multirow[t]{2}{*}{ Chen et al. [20] } & Laparoscopic & 32 & $292.8 \pm 65.2$ & $225.0 \pm 164.1$ & $8(25.0)$ & $29.7 \pm 15.4$ & $9.0 \pm 2.7$ & - & - & - & - \\
\hline & Open & 44 & $302.9 \pm 76.4$ & $1139.0 \pm 656.8$ & $33(75.0)$ & $27.8 \pm 11.0$ & $11.2 \pm 3.3$ & - & - & - & - \\
\hline \multirow[t]{2}{*}{ Ditto et al. [25] } & Laparoscopic & 60 & $215.9 \pm 61.6$ & $50 \pm 112.5$ & $1(2)$ & $25.4 \pm 10.0$ & $4 \pm 2$ & - & - & - & - \\
\hline & Open & 60 & $175.2 \pm 32.1$ & $200 \pm 112.5$ & $3(5)$ & $34.6 \pm 13.5$ & $6 \pm 2.8$ & - & - & - & - \\
\hline \multirow[t]{2}{*}{ Frumovitz et al. [26] } & Laparoscopic & 35 & - & $319.0 \pm 492.0$ & $11(31.4)$ & - & - & $13.5 \pm 4.5$ & $3(8.6)$ & - & - \\
\hline & Open & 54 & - & $548.0 \pm 387.5$ & $15(27.8)$ & - & - & $13 \pm 9.3$ & $2(3.7)$ & - & - \\
\hline \multirow[t]{2}{*}{ Ghezzi et al. [27] } & Laparoscopic & 50 & - & - & 0 & $21 \pm 10.3$ & $6 \pm 2.8$ & - & $3(6.0)$ & - & - \\
\hline & Open & 48 & - & - & $4(8)$ & $23 \pm 10.8$ & $10 \pm 7.0$ & - & $3(6.2)$ & - & - \\
\hline \multirow[t]{2}{*}{ Lee et al. [21] } & Laparoscopic & 24 & $334.8 \pm 52.4$ & $414.3 \pm 69.2$ & $5(20.8)$ & $26.3 \pm 11.8$ & - & - & 0 & 90.5 & - \\
\hline & Open & 48 & $326.8 \pm 53.8$ & $836.0 \pm 315.8$ & $23(47.9)$ & $26.8 \pm 13.6$ & - & - & 0 & 93.3 & - \\
\hline \multirow[t]{2}{*}{ Li et al. [22] } & Laparoscopic & 90 & $263.0 \pm 67.6$ & $369.8 \pm 249.9$ & - & $21.3 \pm 8.4$ & - & $10.7 \pm 7.2$ & - & - & - \\
\hline & Open & 35 & $217.2 \pm 71.6$ & $455.1 \pm 338.1$ & - & $18.8 \pm 9.5$ & - & $8.6 \pm 6.8$ & - & - & \\
\hline \multirow[t]{2}{*}{ Lim et al. [23] } & Laparoscopic & 18 & $308.0 \pm 66.0$ & $425 \pm 225$ & - & $17 \pm 7.5$ & $5.5 \pm 1.5$ & $19.5 \pm 10.3$ & - & - & \\
\hline & Open & 30 & $240.0 \pm 90.0$ & $500 \pm 1455$ & - & $21.0 \pm 11.8$ & $6 \pm 6.5$ & $21.0 \pm 11.8$ & - & - & \\
\hline \multirow[t]{2}{*}{ Malzoni et al. [28] } & Laparoscopic & 65 & $196.0 \pm 14.5$ & $55.0 \pm 12.5$ & - & $23.5 \pm 5.1$ & - & $10 \pm 2$ & - & 92.4 & - \\
\hline & Open & 62 & $152.0 \pm 19.8$ & $145.0 \pm 41.3$ & - & $25.2 \pm 6.2$ & - & $13 \pm 2.5$ & - & 93.6 & - \\
\hline \multirow[t]{2}{*}{ Nam et al. [24] } & Laparoscopic & 263 & $246.8 \pm 84.8$ & $379.6 \pm 350.0$ & $76(28.9)$ & - & - & $7.2 \pm 1.5$ & $1(0.4)$ & 92.8 & 95.2 \\
\hline & Open & 263 & $247.2 \pm 86.3$ & $541.1 \pm 730.0$ & $106(40.3)$ & - & - & $7.5 \pm 4.3$ & $2(0.8)$ & 94.4 & 96.4 \\
\hline \multirow[t]{2}{*}{ Toptas et al. 2014} & Laparoscopic & 22 & - & - & - & - & - & - & $1(4.5)$ & - & - \\
\hline & Open & 46 & - & - & - & - & - & - & $1(2.2)$ & - & - \\
\hline \multirow[t]{2}{*}{ Zakashansky et al. [30] } & Laparoscopic & 30 & $318.5 \pm 66.0$ & $200.0 \pm 125.0$ & 0 & $31.0 \pm 12.8$ & - & - & - & - & - \\
\hline & Open & 30 & $242.5 \pm 69.5$ & $520.0 \pm 375.0$ & $5(16.7)$ & $21.8 \pm 8.5$ & - & - & - & - & - \\
\hline
\end{tabular}


to assess the funnel plot asymmetry; the significance was set at $p<0.05$ level.

\section{Results}

\section{Description of the studies}

The selection process and result are schematically illustrated in Fig. 1. A total of 12 cohort studies were identified, all of which were accessible in full-text format. We established a database according to the information extracted from each article. Detailed characteristics of the 11 studies are listed in Table 1. A total of 754 LRH and $785 \mathrm{RH}$ cases were included into our meta-analysis. Quality assessment of the studies was performed using the NOS method. The results ranged from a star rating of 6-9 (with a mean star rating of 7.75), with a higher value indicating the better methodology (Table 2).

The majority of the patients in 5 studies were of Asian origin and consisted of a total of 847 patients (55.0 \%) [20-24]. The remaining 7 studies were European and American, comprising692 patients (39.9\%) [25-31]. Inclusion of patients was limited to those defined with FIGO stage IA1 [with lymph vascular space invasion (LVSI)] to IIA cervical cancer. The mean age ranged between 40.5 and 53.0 years. The reported BMI of Asian (means ranging between 22.4 and $24.9 \mathrm{~kg} / \mathrm{m}^{2}$ ) was different from that of European (with means ranging between 23.0 and $29.0 \mathrm{~kg} / \mathrm{m}^{2}$ ). The tumor diameter was similar between the two groups.

The mean duration of the surgical procedure was described in the nine studies (Table 3) [20-25, 28, 30, 31]. The procedure was found to be longer for LRH in most of studies [weighted mean difference $=26.9 \mathrm{~min}(95 \% \mathrm{CI}$ 8.08-45.82; $p<0.05$ ] (Fig. 2). The mean operative time for the laparoscopic technique was $(251.5 \pm 78.3) \mathrm{min}$, whereas it shortened to $(240.0 \pm 85.1) \mathrm{min}$ for the open technique. In nine studies [20-26, 28, 30,31], a reduction of blood loss was seen in the LRH vs. RH group [weighted mean difference $=-268.4 \mathrm{~mL}(95 \% \mathrm{CI}-361.6,-175.1 ; p<$ 0.01] (Table 3; Fig. 2). The mean blood loss was (285.4 \pm $311.1) \mathrm{mL}$ in LRH compared with $(524.1 \pm 650.8) \mathrm{mL}$ in $\mathrm{RH}$, but the risk of requiring a blood transfusion was not significantly different in the laparoscopy and laparotomy groups ( $\mathrm{OR}=0.11,95 \% \mathrm{CI}$ : 0.01 to1.01; $p=0.05$; Fig. 2 ).

The mean hospital stay was shorter for LRH patients (weighted mean difference $=-3.22$ days; $95 \%$ CI-4.21 to -2.23 days; $p<0.01$; Fig. 2). There was no

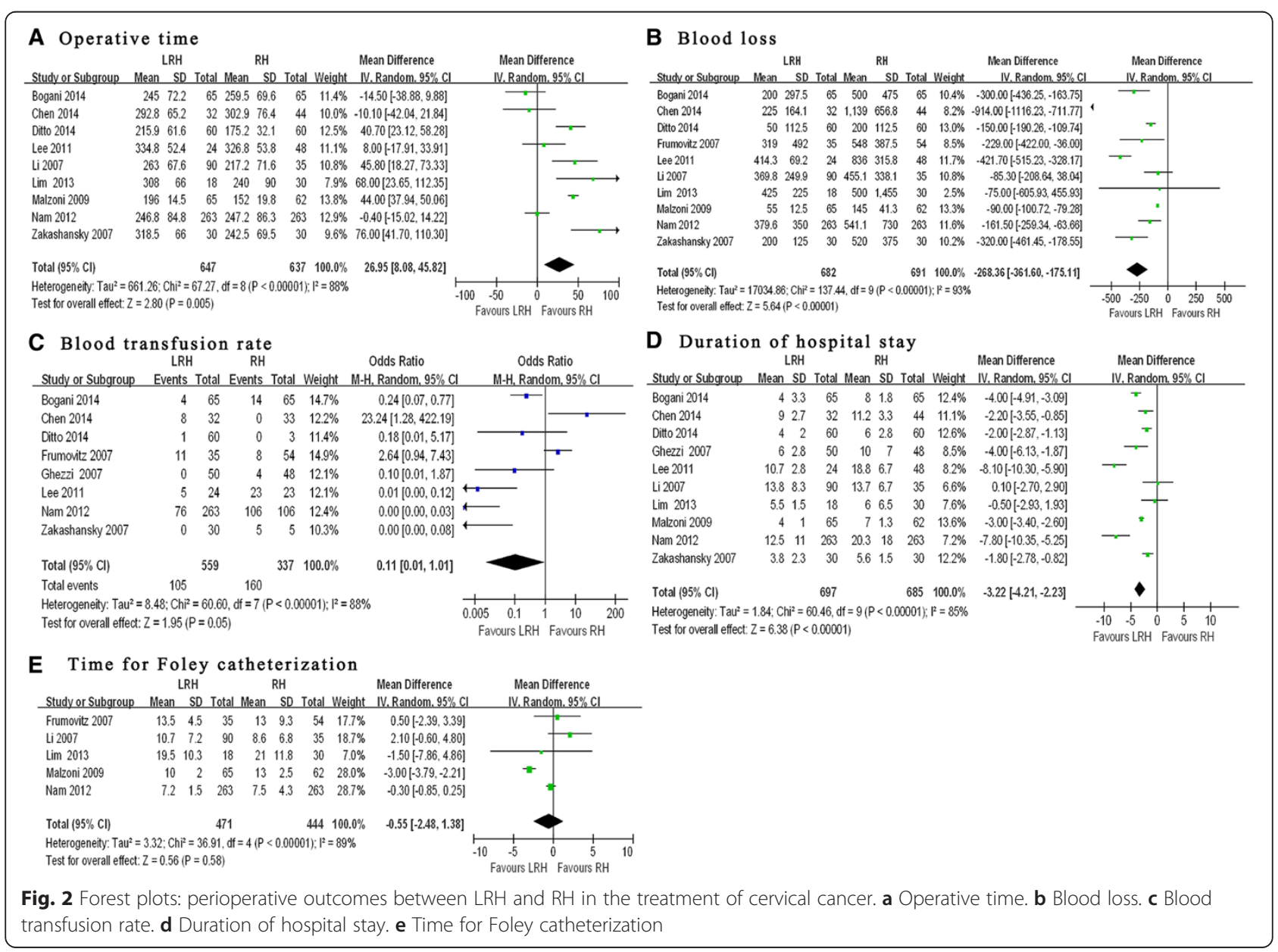




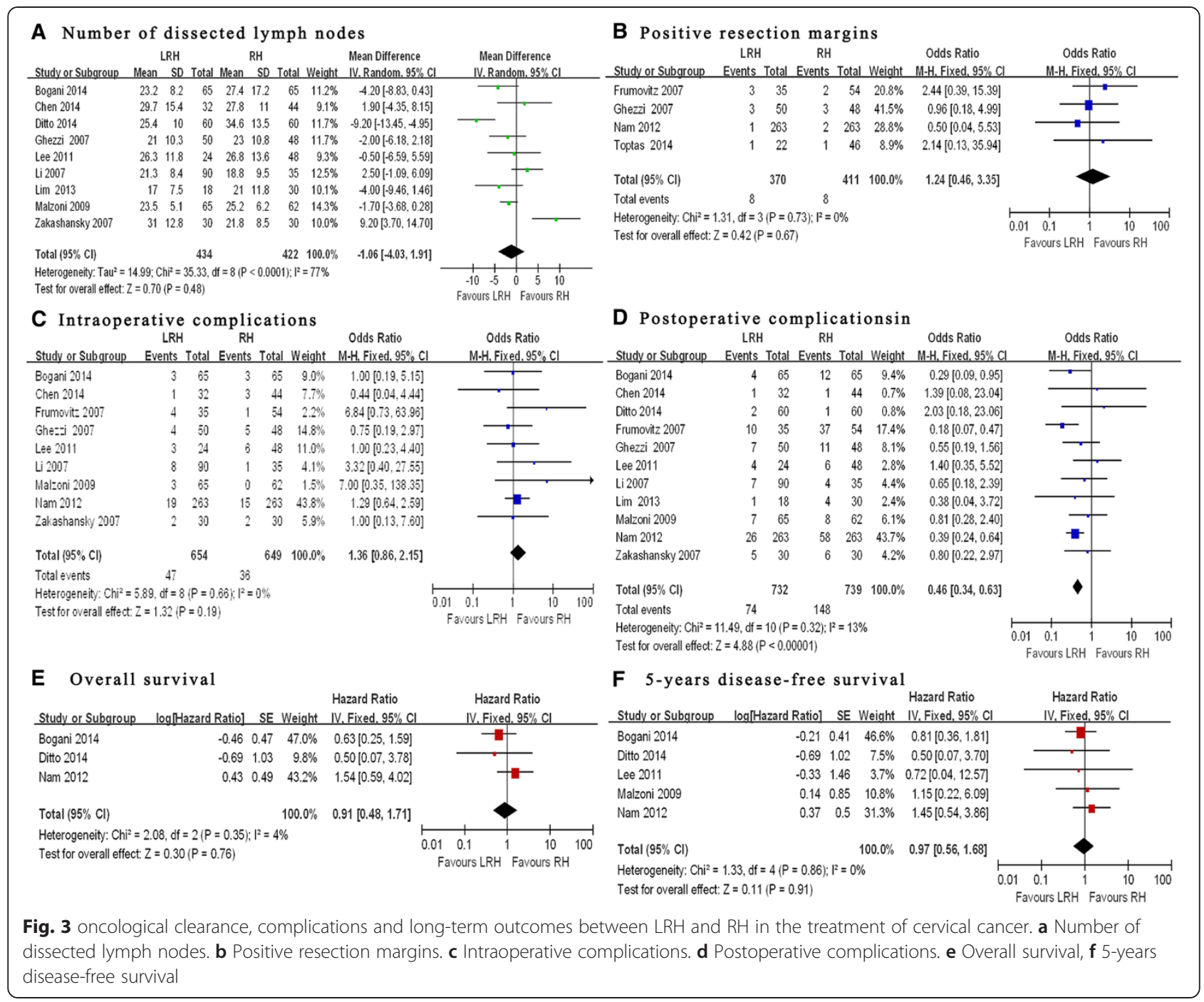

difference between the two groups in the time for Foley catheterization (weighted mean difference $=$ -0.55 days; $95 \%$ CI -2.48 to 1.38 days; $p=0.58$; Fig. 2).

The number of dissected lymph nodes reported in eight studies (Table 3) [20-23, 25, 27, 28, 30, 31] showed comparable difference in both techniques (weighted mean difference $=-1.06 ; 95 \% \mathrm{CI}-4.03$ to $1.91 ; p=0.48$; Fig. 3). None of the studies reported a significant difference in positive resection margins using $\mathrm{LRH}$ and $\mathrm{RH}$ $(\mathrm{OR}=1.24 ; 95$ \% CI 0.46-3.35; $p=0.67$; Fig. 3).

The rate of intraoperative complications was similar in the two groups (6.4 \% LRH vs. $4.9 \% \mathrm{RH}$; OR $=1.36$; $95 \%$ CI $0.86-2.15 ; p=0.19$ Fig. 3; Table 4). Bladder injury occurred in $3.0 \%$ of the LRH patients compared with $2.2 \%$ of the $\mathrm{RH}$ patients $(p=0.309)$. Urethral injury was found in $1.2 \%$ in LRH group compared with of $0.8 \%$ in $\mathrm{RH}$ group $(p=0.425)$. Bowel injury was found in $0.3 \%$ of patients in both groups $(p=0.992)$. Vascular injury occurred in $1.5 \%$ of the LRH patients and in $1.4 \%$ of the $\mathrm{RH}$ patients $(p=$ 0.809) [20-22, 24, 26-28, 30, 31].

Postoperative complications were addressed in 11 studies (Additional file 1) [20-28, 30, 31]. The rate of postoperative surgical complications was lower for LRH versus RH groups (10.1 vs. $20.1 \%$; OR $=0.46 ; 95 \%$ CI $0.34-0.63$; $p<0.001$; Fig. 3). The rates of wound infection $(0.14 \% \mathrm{vs.}$ $0.94 \%, p=0.034)$, febrile morbidity ( $1.91 \%$ vs. $4.74 \%, p=$ $0.004)$, wound dehiscence $(0.41 \%$ vs. $2.30 \%, p=0.002)$ and ileus $(0.82 \%$ vs. $2.30 \%, p=0.022)$ were higher in the $\mathrm{RH}$ group compared to the LRH groups, where the difference was statistically significant. The rates of urinary tract infections, pelvic abscess, postoperative bleeding and ureteral stricture were also higher in the RH group, but these outcomes did not reached statistical significance. In contrast the rates of urinary tract fistula formation were higher in the LRH group without statistical significance. 
Table 4 Perioperative complications

\begin{tabular}{|c|c|c|c|c|c|c|c|}
\hline \multirow[t]{2}{*}{ References } & \multirow[t]{2}{*}{ Approach } & \multirow[t]{2}{*}{ Number } & \multicolumn{4}{|c|}{ Intra-operative complication } & \multirow[b]{2}{*}{ Others } \\
\hline & & & Bladder injury & Urethral injury & Bowel injury & Vascular injury & \\
\hline \multirow[t]{2}{*}{ Bogani et al. [31] } & Laparoscopic & 65 & 1 & 1 & 0 & 0 & 1 \\
\hline & Open & 65 & 0 & 0 & 0 & 2 & 1 \\
\hline \multirow[t]{2}{*}{ Chen et al. [20] } & Laparoscopic & 32 & 1 & 0 & 0 & 0 & 0 \\
\hline & Open & 44 & 0 & 2 & 0 & 1 & 0 \\
\hline \multirow[t]{2}{*}{ Ditto et al. [25] } & Laparoscopic & 60 & 0 & 0 & 0 & 0 & 0 \\
\hline & Open & 60 & 0 & 0 & 0 & 0 & 0 \\
\hline \multirow[t]{2}{*}{ Frumovitz et al. [26] } & Laparoscopic & 35 & 1 & 0 & 0 & 3 & 0 \\
\hline & Open & 54 & 1 & 0 & 0 & 0 & 0 \\
\hline \multirow[t]{2}{*}{ Ghezzi et al. [27] } & Laparoscopic & 50 & 3 & 1 & 0 & 0 & 0 \\
\hline & Open & 48 & 2 & 0 & 1 & 2 & 0 \\
\hline \multirow[t]{2}{*}{ Lee et al. [21] } & Laparoscopic & 24 & 0 & 1 & 0 & 2 & 0 \\
\hline & Open & 48 & 2 & 1 & 0 & 3 & 0 \\
\hline \multirow[t]{2}{*}{ Li et al. [22] } & Laparoscopic & 90 & 4 & 0 & 0 & 4 & 0 \\
\hline & Open & 35 & 0 & 0 & 0 & 1 & 0 \\
\hline \multirow[t]{2}{*}{ Lim et al. [23] } & Laparoscopic & 18 & 0 & 0 & 0 & 0 & 0 \\
\hline & Open & 30 & 0 & 0 & 0 & 0 & 0 \\
\hline \multirow[t]{2}{*}{ Malzoni et al. [28] } & Laparoscopic & 65 & 1 & 0 & 0 & 0 & 2 \\
\hline & Open & 62 & 0 & 0 & 0 & 0 & 0 \\
\hline \multirow[t]{2}{*}{ Nam et al. [24] } & Laparoscopic & 263 & 9 & 6 & 2 & 2 & 0 \\
\hline & Open & 263 & 11 & 3 & 0 & 0 & 1 \\
\hline \multirow[t]{2}{*}{ Zakashansky et al. [30] } & Laparoscopic & 30 & 2 & 0 & 0 & 0 & 0 \\
\hline & Open & 30 & 0 & 0 & 1 & 1 & 0 \\
\hline \multirow[t]{2}{*}{ Total } & Laparoscopic & 732 & $22(3.0)$ & $9(1.2)$ & $2(0.3)$ & $11(1.5)$ & $3(0.4)$ \\
\hline & Open & 739 & $16(2.2)$ & $6(0.8)$ & $2(0.3)$ & $10(1.4)$ & $2(0.3)$ \\
\hline$P$ Value & - & - & 0.309 & 0.425 & 0.992 & 0.809 & 0.6465 \\
\hline
\end{tabular}

Among the total 11 studies, only 3 of them reported 5 -year overall survival $[24,25]$ and in 5 studies, 5-year disease-free survival $[21,24,25,28,31]$. The differences in 5-year OS (HR 0.91, $95 \%$ CI 0.48-1.71; $p=0.76$ ) and DSF (hazard ratio [HR] 0.97, $95 \%$ CI $0.56-1.68 ; p=$ 0.91) were not significant (Fig. 3).

We used the funnel plot (Fig. 4) to examine the results of this meta-analysis. The shape of the funnel plots was nearly symmetrical on both sides of the perpendicular line (real value), indicating that the publication bias of these studies was not obvious. In order to investigate the reliability of the results, we analyzed their sensitivity. A fixed-effect and random-effect model was applied. The differences in the standardized means and the $95 \%$ CIs between the two methods were small. Therefore, both the sensitivity and the publication bias analysis suggested that the meta-analysis results were reliable.

\section{Discussion}

This meta-analysis was to compare LRH to $\mathrm{RH}$ by means of a thorough evaluation of the available evidence. All included studies were nonrandomized, nonblinded, comparative cohort studies. The studies with a high risk of bias were excluded from this metaanalysis. NOS method was applied and combined with a critical appraisal in order to provide a reliable indication of study quality. Unfortunately, the reporting of study methods and potential confounders was insufficient in several studies. Moreover, the selected studies were comparative cohort studies. Thus far, no prospective randomized controlled studies are available. Two prospective randomized controlled trials (RTCs, NCT01258413 and NCT00614211) has been designed in patients with early cervical cancer treated with laparoscopic vs. abdominal radical hysterectomy, 


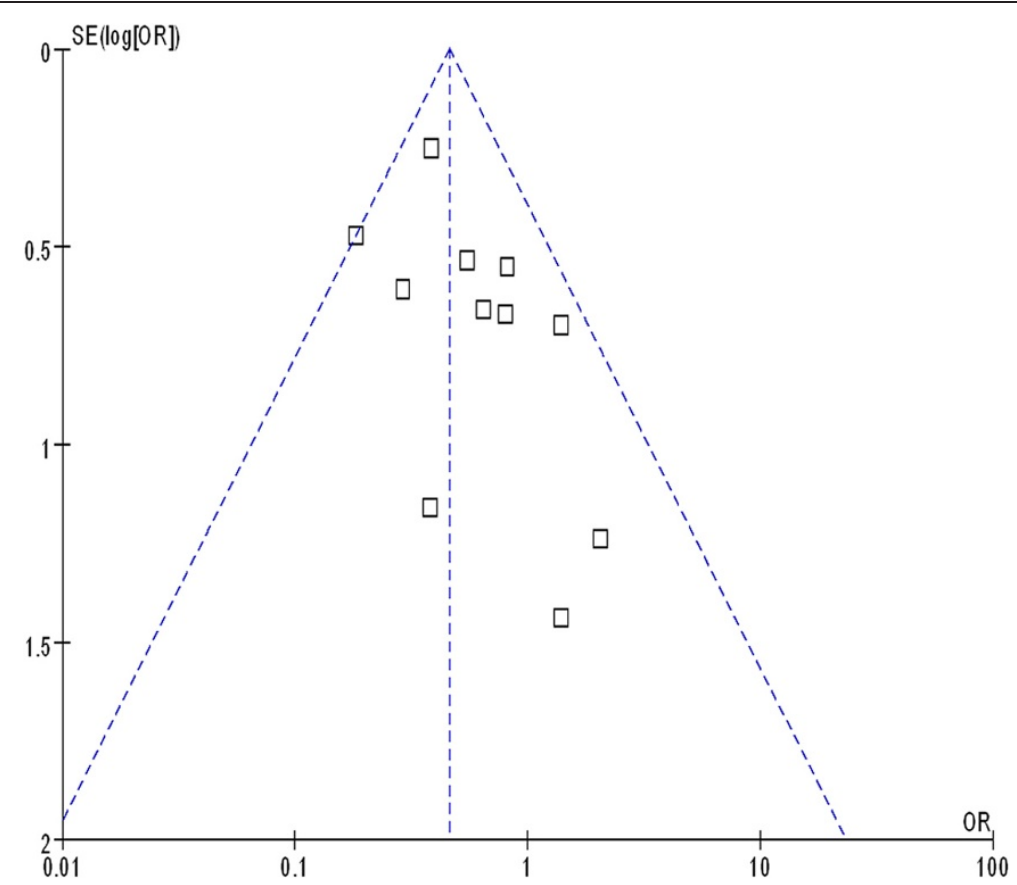

Fig. 4 Funnel plot of studies evaluating the postoperative complications between LRH and RH groups

but has not provided results yet [32 ]. We believe that this present meta-analysis gives an overview of the best available knowledge in this field.

We found that duration of the surgical procedure was longer in LRH vs. RH in the majority of the studies. We also demonstrated that patients treated with LRH recovered faster than those treated with $\mathrm{RH}$ in a functional manner. This is most likely contributed to by the less surgically induced trauma encountered during the procedure. The reduction of blood loss and shorter hospital stay in the LRH group partly supported this hypothesis. Besides these findings, the rates of intraoperative complications were similarly low in both groups. The most frequent intraoperative complications in the LRH group were injuries to the organs such as bladder, ureter and rectum and to great vessels. The repair of injured vessels most frequently required the conversion of laparoscopy to laparotomy. The rates of postoperative complications were significantly lower in the LRH than in the RH group. This was especially true for infectious complications, febrile morbidity, wound infection and wound dehiscence, all of which have been attributed to the laparotomy itself.

In addition, parametrial disease is an independent predictor of recurrence-free survival of cervical cancer patients. Some researchers believe that LRH is performed using an uterine manipulator, which makes the estimation of adequate vaginal resection difficult, and can potentially lead to tumor spillage, especially when the vagina is opened and the tumor surface is exposed to circulating $\mathrm{CO}_{2}$ [33]. Therefore, objective evidence that LRH can achieve at least the same extent of resection as in $\mathrm{RH}$ should be provided before using them interchangeably. Our meta-analysis did find no differences between the two types of surgery in terms of positive surgical margins and lymph nodes yield. This does suggest that laparoscopically managed patients with cervical cancer undergo a similar extent of surgery as those treated with the conventional $\mathrm{RH}$. So far, no meta-analysis has summarized the long-term survival rate of cervical cancer. Only a few studies reported the survival outcomes. Our analysis showed that survival outcomes of the laparoscopic and classical open modalities were comparable, but statistical difference was hard to assess due to the insufficient data of the selected studies which included the unclear use and duration of adjuvant therapy as well as the limited number of data describing long-term survival after LRH versus $\mathrm{RH}$.. It is plausible that these factors may have influenced the overall and disease-free survival of patients.

This study has some limitations that should be recognized when interpreting the results. Firstly, the cohort studies might be subjected to selection bias. Secondly, case selection may have caused the more advanced cervical cancer cases not to be considered for LRH and thirdly the selected studies in this meta-analysis can be seen as pioneer studies and therefore there is probably a learning curve associated with them that may have influenced the results in a negative manner.

\section{Conclusion}

Our meta-analysis showed that LRH is a safe and feasible procedure to treat the early stage of cervical cancer. 
This was evidently supported by reduced blood loss, lower rates of postoperative complications, and faster functional recovery, with a cost of longer operative time found in LRH groups by our meta-analysis. Other outcomes including lymph nodes yield, positive resection margins, 5-year overall survival and 5-year disease-free survival by the two surgical techniques were similar. Further research in the form of prospective RCTs is warranted to evaluate long-term survival outcomes. In our opinion, future research should be directed at determining oncologic outcome, survival and quality of life in addition to the outcomes reported in this review.

\section{Additional file}

\section{Additional file 1: Appendix 3. Postoperative complications.} (DOCX $30 \mathrm{~kb}$ )

\section{Abbreviations}

LRH: Laparoscopic radical hysterectomy; $\mathrm{RH}$ : Open radical hysterectomy RCTs: Randomized controlled trials; LAVH: Laparoscopic assisted vaginal radical hysterectomy; FIGO: International Federation of Gynecology and Obstetrics; DFS: Disease free survival; OS: Overall survival; LVSI: Lymph vascular space invasion.

\section{Competing interests}

The authors declared no competing interests.

\section{Authors' contributions}

$Y Z$ and $Z Q L$ designed the study; $Y Z W, L D, H C X, Y Z$ and $Z Q L$ coordinated the study; $Y Z W, L D, Y Z$ and $Z Q L$ performed the study; $Y Z, L D$,HCX and $Y Z W$ analyzed the data; $Y Z$ and $Z Q L$ helped to draft the manuscript; $Y Z W$ and LD wrote the manuscript, All authors read and approved the final manuscript.

\section{Authors' information}

Zhiqing Liang: Director of Department of Obstetrics and Gynecology, Southwest Hospital, Third Military Medical University. Vice chairman of Chinese Gynecology Endoscopy Group (CGEG). Standing Committee of Gynecological Oncology Sub-Committee of Chinese Medical Association. Standing Committee of Obstetrics \& Gynecology Sub-Committee of Chinese Medical Association.

\section{Acknowledgments \\ This study was Supported by the National High Technology Research and Development Program of China (863 Program) (Grant No.2012AA021103) ,Science and Technology Program for Public wellbeing of China (Grant No.2013GS500101). The authors would also like to thank Dr Dev Sooranna, Imperial College London and Dr Monica Chung, Texas Tech University Health Sciences Center El Paso, Paul L Foster School of Medicine for editing the manuscript.}

Received: 10 May 2015 Accepted: 16 October 2015

Published online: 24 November 2015

\section{References}

1. Ferlay JSI, Ervik M, Dikshit R, Eser S, Mathers C, Rebelo M, et al. GLOBOCAN 2012 v1.0, Cancer Incidence and Mortality Worldwide: IARC CancerBase No. 11. Lyon, France: International Agency for Research on Cancer; 2013. http:// globocan.iarc.fr, accessed 20 Dec 2014.

2. Jemal A, Bray F, Center MM, Ferlay J, Ward E, Forman D. Global cancer statistics. CA Cancer J Clin. 2011;61(2):69-90.

3. Bansal N, Herzog TJ, Shaw RE, Burke WM, Deutsch I, Wright JD. Primary therapy for early-stage cervical cancer: radical hysterectomy vs radiation. Am J Obstet Gynecol. 2009;201(5):485.e481-489.
4. Nezhat CR, Burrell MO, Nezhat FR, Benigno BB, Welander CE. Laparoscopic radical hysterectomy with paraaortic and pelvic node dissection. Am J Obstet Gynecol. 1992;166(3):864-5.

5. Lee CL, Huang KG, Wang CJ, Lee PS, Hwang LL. Laparoscopic radical hysterectomy using pulsed bipolar system: comparison with conventional bipolar electrosurgery. Gynecol Oncol. 2007;105(3):620-4.

6. Pomel C, Atallah D, Le Bouedec G, Rouzier R, Morice P, Castaigne D, et al. Laparoscopic radical hysterectomy for invasive cervical cancer: 8-year experience of a pilot study. Gynecol Oncol. 2003;91(3):534-9.

7. Ramirez PT, Slomovitz BM, Soliman PT, Coleman RL, Levenback C. Total laparoscopic radical hysterectomy and lymphadenectomy: the M. D. Anderson Cancer Center experience. Gynecol Oncol. 2006;102(2):252-5.

8. Koh W-J, Greer BE, Abu-Rustum NR, Apte SM, Campos SM, Chan J, et al. Cervical cancer. J Natl Compr Canc Netw. 2013;11(3):320-43.

9. Geetha P, Nair MK. Laparoscopic, robotic and open method of radical hysterectomy for cervical cancer: A systematic review. JMAS. 2012;8(3):67-73

10. Kucukmetin A, Jackson KS, Bryant A, Naik R. Laparoscopic Assisted Radical Vaginal Hysterectomy (LARVH) versus radical abdominal hysterectomy (RAH) for the treatment of cervical cancer, A cochrane review. Int J Gynecol Cancer. 2011:21(12):S1345.

11. Stroup DF, Berlin JA, Morton SC, Olkin I, Williamson GD, Rennie D, et al. Meta-analysis of observational studies in epidemiology: a proposal for reporting. Meta-analysis Of Observational Studies in Epidemiology (MOOSE) group. JAMA. 2000;283(15):2008-12.

12. Park JY, Kim DY, Kim JH, Kim YM, Kim YT, Nam JH. Laparoscopic versus open radical hysterectomy for elderly patients with early-stage cervical cancer. Am J Obstet Gynecol. 2012;207(3):195 e191-198.

13. Park JY, Kim DY, Kim JH, Kim YM, Kim YT, Nam JH. Laparoscopic compared with open radical hysterectomy in obese women with early-stage cervical cancer. Obstet Gynecol. 2012;119(6):1201-9.

14. Park JY, Kim DY, Kim JH, Kim YM, Kim YT, Nam JH. Laparoscpic versus open radical hysterectomy in patietns with stage IB2 and lla2 cervical cancer. Int J Gynecol Cancer. 2012;22, E199.

15. Hozo SP, Djulbegovic B, Hozo I. Estimating the mean and variance from the median, range, and the size of a sample. BMC Med Res Methodol. 2005;5:13.

16. Parmar MK, Torri V, Stewart L. Extracting summary statistics to perform meta-analyses of the published literature for survival endpoints. Stat Med. 1998;17(24):2815-34

17. Williamson PR, Smith CT, Hutton JL, Marson AG. Aggregate data metaanalysis with time-to-event outcomes. Stat Med. 2002;21(22):3337-51.

18. Deeks JJ, Dinnes J, D'Amico R, Sowden AJ, Sakarovitch C, Song F, et al. Evaluating non-randomised intervention studies. Health Tech Assess (Winchester, England). 2003;7(27):iii-x. 1-173.

19. DerSimonian R, Laird N. Meta-analysis in clinical trials. Control Clin Trials. 1986;7(3):177-88.

20. Chen CH, Chiu LH, Chang CW, Yen YK, Huang YH, Liu WM. Comparing robotic surgery with conventional laparoscopy and laparotomy for cervical cancer management. Int J Gynecol Cancer. 2014;24(6):1105-11.

21. Lee EJ, Kang H, Kim DH. A comparative study of laparoscopic radica hysterectomy with radical abdominal hysterectomy for early-stage cervical cancer: A long-term follow-up study. Eur J Obstet Gynecol Reprod Biol. 2011;156(1):83-6.

22. Li G, Yan X, Shang H, Wang G, Chen L, Han Y. A comparison of laparoscopic radical hysterectomy and pelvic lymphadenectomy and laparotomy in the treatment of Ib-lla cervical cancer. Gynecol Oncol. 2007;105(1):176-80.

23. Lim YK, Chia YN, Yam KL. Total laparoscopic Wertheim's radical hysterectomy versus Wertheim's radical abdominal hysterectomy in the management of stage I cervical cancer in Singapore: a pilot study. Singapore Med J. 2013;54(12):683-8.

24. Nam JH, Park JY, Kim DY, Kim JH, Kim YM, Kim YT. Laparoscopic versus open radical hysterectomy in early-stage cervical cancer: long-term survival outcomes in a matched cohort study. Ann Oncol. 2012;23(4):903-11.

25. Ditto A, Martinelli F, Bogani G, Gasparri ML, Di Donato V, Zanaboni F, et al. Implementation of laparoscopic approach for type B radical hysterectomy: A comparison with open surgical operations. Eur J Surg Oncol.2015; 41(1):34-9.

26. Frumovitz M, dos Reis R, Sun CC, Milam MR, Bevers MW, Brown J, et al. Comparison of total laparoscopic and abdominal radical hysterectomy for patients with early-stage cervical cancer. Obstet Gynecol. 2007;110(1):96-102. 
27. Ghezzi F, Cromi A, Ciravolo G, Volpi E, Uccella S, Rampinelli F, et al. Surgicopdthologic outcome of laparoscopic versus open radical hysterectomy. Gynecol Oncol. 2007;106(3):502-6.

28. Malzoni M, Tinelli R, Cosentino F, Fusco A, Malzoni C. Total laparoscopic radical hysterectomy versus abdominal radical hysterectomy with lymphadenectomy in patients with early cervical cancer: our experience. Ann Surg Oncol. 2009;16(5):1316-23.

29. Toptas T, Simsek T. Total laparoscopic versus open radical hysterectomy in stage IA2-IB1 cervical cancer: disease recurrence and survival comparison. J Laparoendosc Adv Surg Tech A. 2014;24(6):373-8.

30. Zakashansky K, Chuang L, Gretz H, Nagarsheth NP, Rahaman J, Nezhat FR. A case-controlled study of total laparoscopic radical hysterectomy with pelvic lymphadenectomy versus radical abdominal hysterectomy in a fellowship training program. Int J Gynecol Canc. 2007;17(5):1075-82.

31. Bogani G, Cromi A, Uccella S, Erati M, Casarin J, Pinelli C, et al. Laparoscopic Versus Open Abdominal Management of Cervical Cancer: Long-Term Results From a Propensity-Matched Analysis. J Minim Invasive Gynecol. 2014;21(5):857-62.

32. Obermair A, Gebski V, Frumovitz M, Soliman PT, Schmeler KM, Levenback C, et al. A phase III randomized clinical trial comparing laparoscopic or robotic radical hysterectomy with abdominal radical hysterectomy in patients with early stage cervical cancer. J Minim Invasive Gynecol. 2008;15(5):584-8.

33. Koehler C, Gottschalk E, Chiantera V, Marnitz S, Hasenbein K, Schneider A. From laparoscopic assisted radical vaginal hysterectomy to vaginal assisted laparoscopic radical hysterectomy. BJOG. 2012;1 19(2):254-62.

\section{Submit your next manuscript to BioMed Central and take full advantage of:}

- Convenient online submission

- Thorough peer review

- No space constraints or color figure charges

- Immediate publication on acceptance

- Inclusion in PubMed, CAS, Scopus and Google Scholar

- Research which is freely available for redistribution 